\title{
Relationship between changes in selected thrombotic and inflammatory factors, echocardiographic parameters and the incidence of venous thrombosis after pacemaker implantation based on our own observations
}

\author{
Jacek Lelakowski1', Teresa Barbara Domagała ${ }^{2,3}$, Anna Rydlewska ${ }^{1}$, Rafał Januszek², \\ Katarzyna Kotula-Horowitz², Jacek Majewski', Andrzej Ząbek', Barbara Małecka ${ }^{1}$
}

1Department of Electrocardiology, Institute of Cardiology, The John Paul II Hospital, School
of Medicine, Jagiellonian University, Cracow, Poland
2Department of Internal Medicine, School of Medicine, Jagiellonian University, Cracow,
Poland
3Department of Medical Biochemistry, School of Medicine, Jagiellonian University, Cracow,
Poland

Submitted: 27 March 2011

Accepted: 31 August 2011

Arch Med Sci 2012; 8, 6: 1027-1034

DOI: $10.5114 /$ aoms.2012.28600

Copyright (C) 2012 Termedia \& Banach

\section{Corresponding author:} Prof. Jacek Lelakowski MD, PhD 30/64 Wybickiego 31-302 Cracow, Poland Phone: +48 504299354 , +48126142277 Fax: +48 126332399 E-mail: lelakow@szpitaljp2. krakow.pl

\begin{abstract}
Introduction: Thrombosis (VTh) is a rare dangerous complication of pacemaker implantation (PM). The aim of the study was to determine the dynamics of change in selected thrombotic and inflammatory factors after PM.

Material and methods: The study involved 81 patients (30 female, mean age: 71.1 years) with PM, divided into two groups. Group A (71 patients) consisted of patients without VTh, whereas group B (10 patients) comprised the patients with VTh. A transthoracic echocardiogram (TTE) and a venous ultrasound (VU) examination were performed. The levels of D-dimers, fibrinogen, tissue factor (TF), factor VII, plasminogen activator inhibitor-1 (PAI-1), interleukin-6 (IL-6) and high-sensitivity C-reactive protein (hsCRP) were determined in the venous blood. After PM, the TTE and VU examinations were repeated at 6 and 12 months, and blood analyses were performed within 7 days after PM, and subsequently at 6 and 12 months.

Results: In 10 patients of group B, symptomatic VTh occurred at a mean time of 13.06 months after PM. Initially, the levels of IL-6, hsCRP, D-dimers, fibrinogen, TF, VII factor and PAI-1 were considerably higher in group B than in group A. In all patients the levels of these factors kept on increasing for up to 7 days after the procedure. In group A they subsequently decreased, whereas in group B they continued to rise.

Conclusions: Increased levels of inflammatory and thrombotic factors were observed in patients with VTh before and after PM. The factors of highest risk of VTh occurrence were D-dimers, fibrinogen and TF.
\end{abstract}

Key words: venous thrombosis, cardiac pacing, inflammatory and thrombotic factors.

\section{Introduction}

Major complications of pacemaker implantation include venous occlusion [1], thrombus formation in cardiac cavity [2, 3], superior vena cava syndrome $[4,5]$, recurrent venous thrombotic events and post-thrombo- 
tic syndrome [6]. Symptoms of thrombosis occur in about $0.5-5 \%$ and life-threatening blood clots in 0.6-3.5\% of all pacemaker implantation cases [6]. Approximately $30-50 \%$ of the patients develop phlebitis as a complication of transvenous lead placement. It is most frequently subclavian, brachial or axillary phlebitis [6].

Rozmus et al. [7] performed a meta-analysis (a total of 711 patients) of venous thrombosis (VT) in patients after pacemaker implantation (PM). Abnormal venography results were found in $38 \%$ of the patients, venous occlusion in $11 \%$, and symptomatic VT in only $2.6 \%$ of the patients.

Subclavian or brachiocephalic vein occlusion is a complication that develops in $8-21 \%$ of the patients, whereas superior vena cava occlusion leading to superior vena cava syndrome develops in $0.03-0.4 \%$ [8].

Studies of VT as a complication of pacemaker implantation have shown ambiguous results. A number of risk factors for the development of this complication have been identified $[1,6,7]$. The present study is an attempt to explain the dynamics of change in selected hemodynamic and biochemical parameters (prothrombotic and proinflammatory markers) predisposing to the development of thrombotic events after the implantation of a pacemaker.

\section{Material and methods}

The study group comprised 81 patients (30 females, 51 males, mean age: $71.1 \pm 7.4$ years) with a cardiac pacemaker. Patients were divided according to the absence or presence of VT in the postimplantation period into group A (28 females, 43 males; mean age: $71.2 \pm 7.6$ years) and group $B$ ( 2 females, 8 males; mean age: $72.6 \pm 7.2$ years), respectively.

The exclusion criteria were: (1) lack of informed consent, (2) upper extremity venous stenosis before implantation, (3) inability to obtain diagnostic images, (4) artificial valves, status after percutaneous coronary interventions, patients qualified for pacemaker upgrade, and chronic anticoagulation and anti-aggregation therapy.

All patients were subsequently followed up for 18 months. During follow-up 29 patients were excluded at 7 days and 3 more at 6 months from group $A$ after initiation of anticoagulation treatment; therefore 42 patients and 39 patients were available for analysis at 6 and 12 months, respectively. Three patients from group $B$, who developed thrombosis, were excluded at 6 months; therefore 7 patients were re-examined at 12 months. In the remaining subjects thrombotic events occurred at a later time. Both groups were comparable with respect to age and gender.

Thirty-two patients received anticoagulation therapy (acenocoumarol), 31 diuretics, 49 anti- hypertensive medications (ACE-I, $\beta$-blockers), 30 statins and 24 digoxin during the observation period. Twenty-seven patients had a history of myocardial infarction, 4 of cerebral stroke, 31 were diagnosed with heart failure, 30 with atherosclerosis and 49 with arterial hypertension.

Transthoracic echocardiography (TTE) was performed with a Prosound $\alpha 10$, Aloka echo machine. Left ventricular ejection fraction (LVEF) was calculated using Simpson's method in the apical fourand two-chamber view. Left ventricular diastolic function was evaluated based on early flow propagation velocity (Vp) by color M-mode Doppler in the apical four-chamber view. Left ventricular end-diastolic diameter (LVEDD) was measured in parasternal long-axis view in the basal segments using $\mathrm{M}$-mode echocardiography.

Upper extremity ultrasound (VU) was performed using a Vivid 7 Expert device and linear probe 5-13 MHz to assess venous systems of the left and right upper limb, shoulder girdle and neck. The morphology and flow were assessed using a duplex pulsed-Doppler/real-time system. Heart and vascular examinations (TTE, VU) were performed before and at 6 and 12 months after PM.

Blood was drawn from the antecubital vein at 7 o'clock after obtaining individual written informed consent. Citrated plasma and sera were stored at $-70^{\circ} \mathrm{C}$ until assay. In citrated plasma samples we determined D-dimer concentrations by use of an immunoturbidimetric method, fibrinogen levels using a coagulometric method, plasminogen activator inhibitor-1 (PAI-1) and tissue factor (TF) by immunoenzymatic assay, and factor VII activity based on the prothrombin time. In blood serum we measured high-sensitivity C-reactive protein (hsCRP) using nephelometric methods and IL- 6 by immunoenzymatic assay.

Blood tests were performed before and after pacemaker implantation (on day 7 and at 6 and 12 months).

\section{Statistical analysis}

Descriptive statistics (arithmetic mean $(x)$, standard deviation (SD), median (Me), minimum (min) and maximum (max) value, number of patients $(n)$ ) were used to describe hemodynamic and biochemical parameters.

Unpaired Student's t-test or Mann-Whitney $U$ test was used to test for differences between groups. Paired Student's $t$-test or Wilcoxon test was used to test for differences between measurements. The rate of change between study groups was calculated from differences between the consecutive measurements (deducting the value from the preceding one) for each variable in each patient. Receiver operating characteristic curve (ROC) analysis was used to determine the diagnostic strength 
of the hemodynamic and biochemical parameters in predicting the risk of thrombosis. The cut-off point was calculated for each parameter based on Youden's index.

Logistic regression analysis was used to calculate odds ratio (OR) and 95\% confidence interval and define the impact of specific parameters on the risk of thrombosis.

A $p$ value $\leq 0.05$ was considered as statistically significant. Calculations were performed using the Statistica 9.0 and MedCalc packages.

The present study was approved by the JagielIonian University Bioethics Committee (approval no. KBET/63/B/2009).

\section{Results}

The two groups did not differ with respect to the pacing mode. Patients in group $B$ had a significantly lower left ventricular ejection fraction, larger diastolic dimensions and impaired inflow as compared with group A. During the 18-month follow-up period the ejection fraction and the early flow Vp increased, whereas the diastolic dimension decreased (Table I, Figure 1).

The symptoms of VT occurred in 10 patients in group $B$ at a mean of 13.06 months (7-17 months), i.e. in $12.3 \%$ of the whole study population. The subclavian and brachiocephalic veins on the side of PM were occluded.
Initially plasma levels of prothrombotic (D-dimers, fibrinogen, TF, VII, PAI-1) and proinflammatory (IL-6, hs(RP) markers were markedly higher in group $B$ than in group $A$. In all study patients the values continued to rise until the $7^{\text {th }}$ day after PM. At 6 and 12 months after the procedure the trend towards increasing plasma levels of these markers was observed only in group B. In group A the levels returned to normal (Table II, Figures 2 and 3). The cut-off values for hemodynamic parameters and biochemical markers that confer increased risk of VT $(p<0.001)$ were calculated using ROC curve analysis (Table III). The univariate analysis (Table IV) and ROC curve analysis identified D-dimers, fibrinogen and TF as the risk factors for thrombotic events.

The small sample size did not allow for multivariate analysis of our data.

\section{Discussion}

In this paper we discuss the dynamics of changes in selected echocardiographic parameters, inflammatory molecules and thrombotic factors, in patients before pacemaker implantation and after the operation, that correlate with the risk of venous thrombosis. The number of the patients, especially in group B (with vein thrombosis) is very limited, which may slightly affect the accuracy of our findings. Nevertheless, despite the small sample size, this study is of clinical importance as its findings may help screen high-risk patients to select those

Table I. Differences in hemodynamic parameters between patients with (group B) and without venous thrombosis (group A) before (0) and at 6 and 12 months after pacemaker implantation

\begin{tabular}{|c|c|c|c|c|c|c|c|}
\hline \multirow{2}{*}{$\begin{array}{l}\text { Hemodynamic } \\
\text { parameters }\end{array}$} & \multicolumn{3}{|c|}{ Group A $(n=71)$} & \multicolumn{3}{|c|}{ Group B $(n=10)$} & \multirow[t]{2}{*}{ Value of $p$} \\
\hline & $x \pm \mathrm{SD}$ & $\mathrm{Me}$ & Min-max & $x \pm S D$ & $\mathrm{Me}$ & Min-max & \\
\hline$E F(0)$ & $53.7 \pm 15.3$ & 55 & $20-78$ & $33.3 \pm 5.2$ & 33 & $25-45$ & 0.0001 \\
\hline LVEDD (0) & $52.7 \pm 9.9$ & 48 & $42-72$ & $66.4 \pm 4.0$ & 68 & $59-72$ & 0.0001 \\
\hline \multirow[t]{2}{*}{$V p(0)$} & $43.1 \pm 4.3$ & 45 & $34-48$ & $39.7 \pm 4.4$ & 39 & $33-47$ & 0.023 \\
\hline & \multicolumn{3}{|c|}{$n=42$} & \multicolumn{3}{|c|}{$n=10$} & \\
\hline$E F(6)$ & $55.5 \pm 13.6$ & 57 & $23-78$ & $37.6 \pm 8.3$ & 36 & $25-50$ & 0.0001 \\
\hline LVEDD (6) & $50.4 \pm 8.1$ & 47 & $42-72$ & $61.0 \pm 5.9$ & 61 & $55-69$ & 0.0001 \\
\hline \multirow[t]{2}{*}{$\operatorname{Vp}(6)$} & $43.9 \pm 3.7$ & 45 & $34-48$ & $41.3 \pm 3.9$ & 41 & $33-47$ & 0.046 \\
\hline & \multicolumn{3}{|c|}{$n=39$} & \multicolumn{3}{|c|}{$n=7$} & \\
\hline EF (12) & $55.1 \pm 13.6$ & 57 & $25-78$ & $39.1 \pm 8.6$ & 37 & $29-55$ & 0.001 \\
\hline LVEDD (12) & $50.2 \pm 7.9$ & 46 & $42-72$ & $60.3 \pm 6.5$ & 61 & $48-69$ & 0.0001 \\
\hline $\operatorname{Vp}(12)$ & $43.6 \pm 3.9$ & 45 & $35-48$ & $40.4 \pm 3.1$ & 41 & $33-44$ & 0.017 \\
\hline \multirow{2}{*}{$\begin{array}{l}\text { Hemodynamic } \\
\text { parameters }\end{array}$} & \multicolumn{3}{|c|}{ Group A } & \multicolumn{3}{|c|}{ Group B } & \\
\hline & $\begin{array}{c}0 \text { vs. } 6 \\
\text { Value of } p\end{array}$ & $\begin{array}{c}6 \text { vs. } 12 \\
\text { Value of } p\end{array}$ & $\begin{array}{c}0 \text { vs. } 12 \\
\text { Value of } p\end{array}$ & $\begin{array}{c}0 \text { vs. } 6 \\
\text { Value of } p\end{array}$ & $\begin{array}{c}6 \text { vs. } 12 \\
\text { Value of } p\end{array}$ & $\begin{array}{c}0 \text { vs. } 12 \\
\text { Value of } p\end{array}$ & \\
\hline EF & 0.001 & 0.299 & 0.103 & 0.043 & 0.310 & 0.063 & \\
\hline LVEDD & $<0.001$ & 0.715 & 0.002 & 0.043 & 0.465 & 0.046 & \\
\hline$V p$ & 0.001 & 0.082 & 0.128 & 0.068 & 0.345 & 0.726 & \\
\hline
\end{tabular}



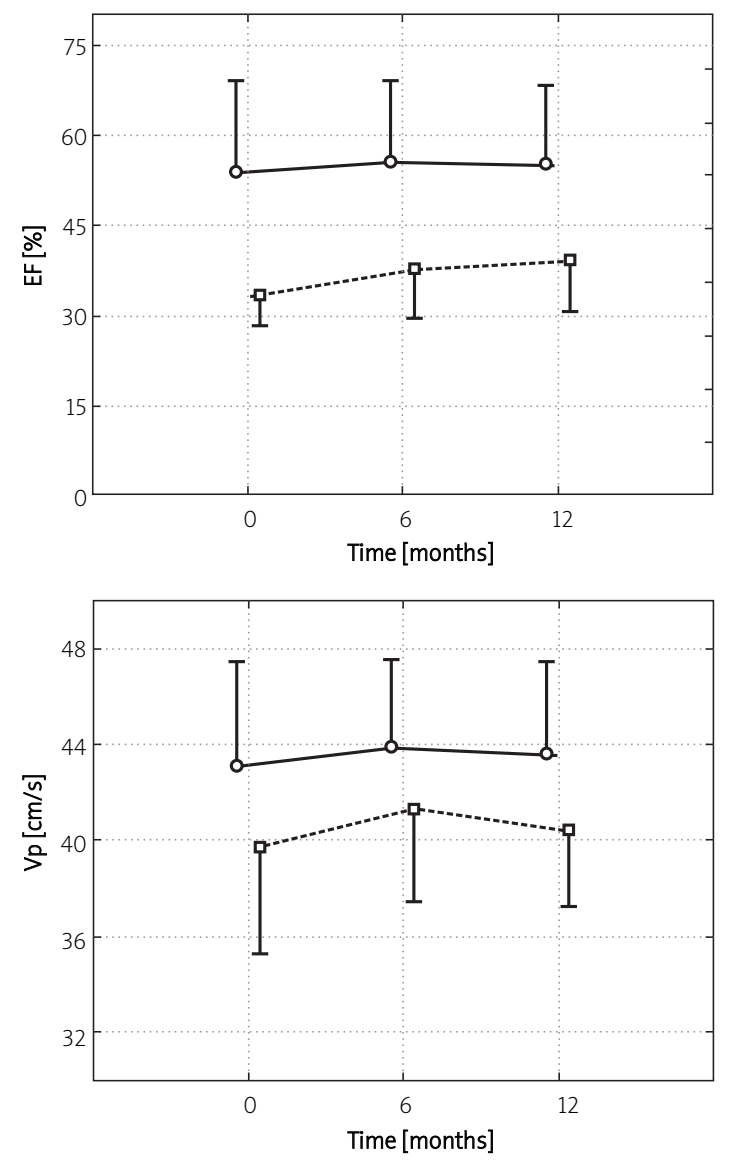

who require early anticoagulation therapy. It is the assessment of the dynamics of changes in certain hemodynamic and biochemical parameters after the pacemaker implantation procedure that makes the paper original.

Venous stasis after vein ligation, increased blood viscosity and endothelial injury (Virchow's triad) in the presence of endocavitary leads may trigger local vascular wall inflammation and activate the coagulation system. This results in a release of the inflammatory factors IL- 6 and hsCRP, and coagulation and fibrinolytic proteins, such as fibrinogen and plasminogen activator inhibitor 1 (PAI-1). A clot narrowing or occluding the vessel lumen is formed at the injury site. Endogenous fibrinolysis and complete clot lysis occur in less than $20 \%$ of the cases [11-16]. Much more frequently (in about $50-70 \%$ of the cases) clot dissolution is impaired and it grows uncontrollably, obstructing the vessel $[10,17]$. The PAI-1 is also involved in the process.

The risk of developing thromboembolic complications remains constant regardless of the time elapsed since implantation [5]. One out of two cases of thrombosis was reported at 1 year after implantation [18], whereas superior vena cava syndrome developed at 6 years after implantation [19]. In a meta-analysis of 6256 patients with a pacemaker at a mean of

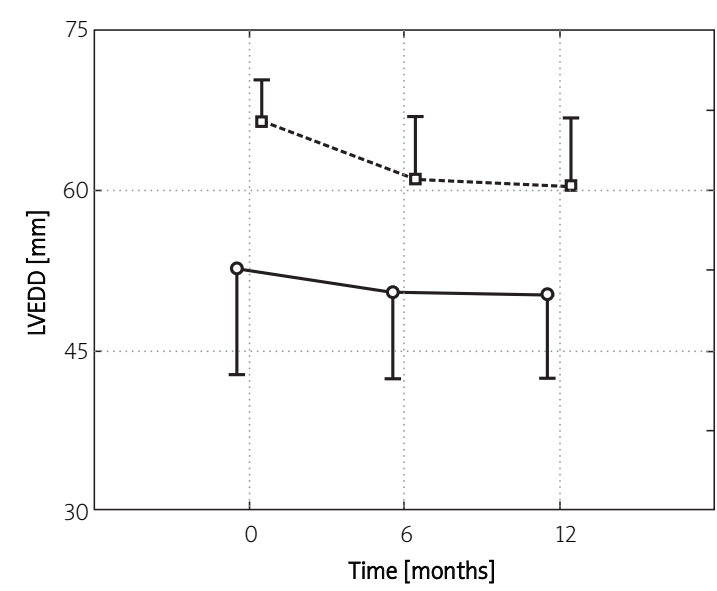

$$
\begin{aligned}
& \text { 호 } x \pm S D \text { Group A } \\
& \text { 포 } x \pm S D \text { Group B }
\end{aligned}
$$

Figure 1. Mean value measurements $(x)$ and standard deviations (SD) of hemodynamic parameters in the study groups

6 months, angiography revealed subclavian or brachiocephalic vein occlusion in $0.35 \%$ of the cases [20] Right atrial thrombus around a pacing lead resulted in cor pulmonale as late as 6 years after pacemaker implantation and at 3.5 years after its removal and leaving the fixed electrode in place [18]. In our group, thrombosis developed at a mean of 13.06 months after pacemaker implantation.

Epidemiological and clinical evidence shows the relationship between biochemical markers of endothelial injury and platelet activation and the risk for developing VT [13], similar to our patient groups. Pathological activation of coagulation and attenuation of fibrinolysis lead to vein thrombosis and obstruction, and may trigger pulmonary embolism. In our study we confirmed the working hypothesis that pacemaker patients with a history of thrombotic events had higher levels of certain prothrombotic and proinflammatory markers of endothelial injury. It is noteworthy that their increased levels in group B were much more frequent prior to the thrombotic event and, in contrast to group A, continued to rise during follow-up. Furthermore, these patients had heart failure, confirmed by reduced left ventricular ejection fraction, increased diastolic dimensions and impaired filling. This is not a novel relationship, because clinical evidence 
Table II. Differences in biochemical parameters between patients with (group B) and without venous thrombosis (group A) before (0) and at 7 days, 6 and 12 months after pacemaker implantation

\begin{tabular}{|c|c|c|c|c|c|c|c|}
\hline \multirow{2}{*}{$\begin{array}{l}\text { Biochemical } \\
\text { parameters }\end{array}$} & \multicolumn{3}{|c|}{ Group A $(n=71)$} & \multicolumn{3}{|c|}{ Group B $(n=10)$} & \multirow[t]{2}{*}{ Value of $p$} \\
\hline & $x \pm S D$ & $\mathrm{Me}$ & Min-max & $x \pm S D$ & $\mathrm{Me}$ & Min-max & \\
\hline D-dimers (0) & $299.5 \pm 99$ & 290 & $121-498$ & $570.2 \pm 55.9$ & 550.0 & $500-665$ & $<0.001$ \\
\hline Fibrinogen (0) & $3.6 \pm 0.8$ & 3.5 & $1.8-5.6$ & $6.1 \pm 1.0$ & 5.65 & 4.9-7.7 & $<0.001$ \\
\hline $\mathrm{TF}(0)$ & $213.7 \pm 54.7$ & 190 & $160-440$ & $390.8 \pm 43.1$ & 389.0 & $320-460$ & $<0.001$ \\
\hline VII (0) & $90.7 \pm 16.6$ & 90 & $60-129$ & $116.2 \pm 8.4$ & 120.0 & $100-126$ & $<0.001$ \\
\hline PAI-1 (0) & $11.7 \pm 4.7$ & 11 & $5-23$ & $21.1 \pm 1.9$ & 22.0 & $18-23$ & $<0.001$ \\
\hline IL-6 (0) & $2.8 \pm 1.7$ & 2.2 & $0.7-8.3$ & $4.7 \pm 2.0$ & 4.40 & $2.1-8.6$ & 0.001 \\
\hline \multirow[t]{2}{*}{ hsCRP (0) } & $2.1 \pm 1.2$ & 2 & $0.5-5$ & $4.9 \pm 0.7$ & 5.0 & $4.0-6.0$ & $<0.001$ \\
\hline & \multicolumn{3}{|c|}{$n=71$} & \multicolumn{3}{|c|}{$n=10$} & \\
\hline D-dimers (7) & $312.2 \pm 106.3$ & 324 & $126-525$ & $592.4 \pm 65.8$ & 575.0 & $510-700$ & $<0.001$ \\
\hline Fibrinogen (7) & $3.6 \pm 0.8$ & 3.5 & $1.8-5.6$ & $6.6 \pm 0.8$ & 6.74 & $5.6-7.9$ & $<0.001$ \\
\hline $\operatorname{TF}(7)$ & $226.1 \pm 70.9$ & 200 & $160-459$ & $425.8 \pm 37.5$ & 430.0 & $360-470$ & $<0.001$ \\
\hline VII (7) & $91.4 \pm 17.0$ & 90 & $60-130$ & $132.8 \pm 8.7$ & 132.0 & $120-145$ & $<0.001$ \\
\hline PAI-1 (7) & $13.1 \pm 5.3$ & 12 & $6-26$ & $25.3 \pm 1.9$ & 25.50 & $22-28$ & $<0.001$ \\
\hline IL-6 (7) & $3.6 \pm 1.9$ & 3.3 & $0.8-8.8$ & $5.5 \pm 2.0$ & 5.11 & $2.3-9.3$ & 0.004 \\
\hline \multirow[t]{2}{*}{ hsCRP (7) } & $3.2 \pm 1.8$ & 3 & $1-8$ & $9.9 \pm 2.1$ & 9.5 & $8-14$ & $<0.001$ \\
\hline & \multicolumn{3}{|c|}{$n=42$} & \multicolumn{3}{|c|}{$n=10$} & \\
\hline D-dimers (6) & $304.7 \pm 102.9$ & 310 & $122-510$ & $598.4 \pm 63.6$ & 595 & $510-700$ & $<0.001$ \\
\hline Fibrinogen (6) & $3.3 \pm 0.7$ & 3.3 & $1.8-5.5$ & $6.7 \pm 0.9$ & 6.75 & $5.6-8$ & $<0.001$ \\
\hline TF (6) & $218.8 \pm 68.1$ & 192 & $151-445$ & $429.8 \pm 38.3$ & 435 & $360-480$ & $<0.001$ \\
\hline VII (6) & $85.7 \pm 13.5$ & 82 & $62-130$ & $132.8 \pm 8.7$ & 132 & $120-145$ & $<0.001$ \\
\hline PAI-1 (6) & $11.5 \pm 4.8$ & 10 & $5-26$ & $25.8 \pm 1.8$ & 25.5 & $23-29$ & $<0.001$ \\
\hline IL-6 (6) & $3.0 \pm 1.7$ & 2.5 & $0.9-7.9$ & $5.6 \pm 1.9$ & 5.12 & $2.4-9.3$ & $<0.001$ \\
\hline \multirow[t]{2}{*}{ hsCRP (6) } & $2.5 \pm 1.5$ & 2 & $1-8$ & $10.7 \pm 3.2$ & 9.5 & $8-17$ & $<0.001$ \\
\hline & \multicolumn{3}{|c|}{$n=39$} & \multicolumn{3}{|c|}{$n=7$} & \\
\hline D-dimers (12) & $298.9 \pm 102.6$ & 300 & $122-520$ & $835.6 \pm 182.2$ & 865 & $540-1136$ & $<0.001$ \\
\hline Fibrinogen (12) & $3.2 \pm 0.7$ & 3 & $1.8-5.2$ & $9.2 \pm 2.1$ & 9.50 & $6-12$ & $<0.001$ \\
\hline TF (12) & $213.3 \pm 68$ & 187 & $140-445$ & $473.9 \pm 52.1$ & 485 & $380-550$ & $<0.001$ \\
\hline VII (12) & $84.5 \pm 12.4$ & 81 & $62-129$ & $139.2 \pm 10.8$ & 140 & $120-155$ & $<0.001$ \\
\hline PAI-1 (12) & $11.1 \pm 4.6$ & 9 & $5-26$ & $27.9 \pm 2.5$ & 27.5 & $25-32$ & $<0.001$ \\
\hline IL-6 (12) & $2.8 \pm 1.5$ & 2.2 & $0.9-7$ & $8.4 \pm 2.7$ & 8.17 & $5-13.5$ & $<0.001$ \\
\hline hsCRP (12) & $2.4 \pm 1.4$ & 2 & $1-7$ & $17.0 \pm 6.8$ & 17 & $8-28$ & $<0.001$ \\
\hline
\end{tabular}

shows elevated levels of coagulation factors and an increased rate of thrombin generation in heart failure patients $[16,17]$. In order to assess the left ventricular diastolic function a new parameter, early mitral flow Vp, was used. It is insensitive to preload changes and heart rate. Therefore, it seems to be superior to the traditional diastolic function parameters, such as protodiastolic E wave/end-diastolic A wave ratio (E/A ratio), E wave deceleration time (EDT) or isovolumetric relaxation time (IVRT). It also helps to distinguish between normal and pseudonormal left ventricle filling pattern.
In our published and unpublished studies we identified the following risk factors for venous thrombosis following PM: a history of myocardial infarction, temporary external pacing, arrhythmia, venous anomalies, infection, NYHA class III and IV, and smoking. In patients with more than 6 thrombotic risk factors, combined with increased levels of D-dimers, fibrinogen, tissue factor, VII, PAI-1 and inflammatory factors such as IL- 6 and hsCRP, the likelihood of thrombosis is almost 100\% [21].

It is not new, either, because of the well-known effect of elevated fibrinogen on blood viscosity, 

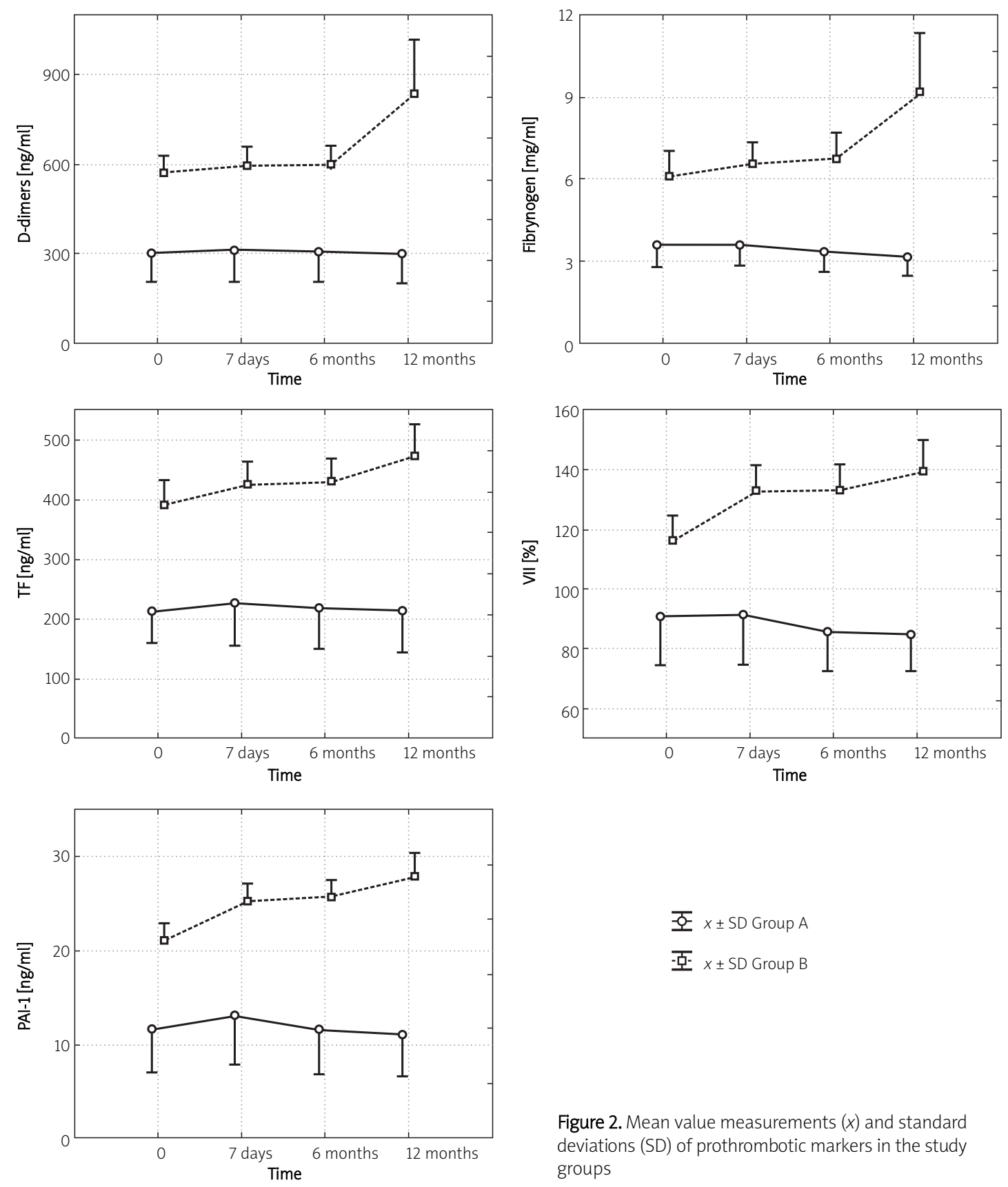

Figure 2. Mean value measurements $(x)$ and standard deviations (SD) of prothrombotic markers in the study groups

platelet aggregation and atherothrombotic vascular lesions. Tissue factor plays the main role in the extrinsic pathway as the cellular receptor for plasma factor VII, whereas low levels of D-dimers exclude venous thrombosis with high probability. Like Korkeila et al. [22], we noticed that patients who initially had elevated levels of thrombotic and inflammatory factors, and who had higher central venous pressure due to heart failure, easily activate thrombosis, which may be initiated by the endothelial injury during the pacemaker lead introduction. The above-mentioned thrombosis risk factors play an important role in this process. Altogether it may lead to vein occlusion.

In the present study univariate analysis (OR) and the area under the ROC curve (AUC) identified D-dimers, fibrinogen and tissue factor as the strongest factors predisposing to thrombotic complications.

It is noteworthy that the patients had not been receiving anticoagulants that might influence levels of the markers, until the event occurred. Anticoagulation as a prophylactic measure following PM, especially in group B, requires further clarification in prospective studies. It seems that it might play a crucial role in the process.

The present findings confirm that the inflammatory markers and coagulation factors increase with pacemaker implantation and rise further in patients 

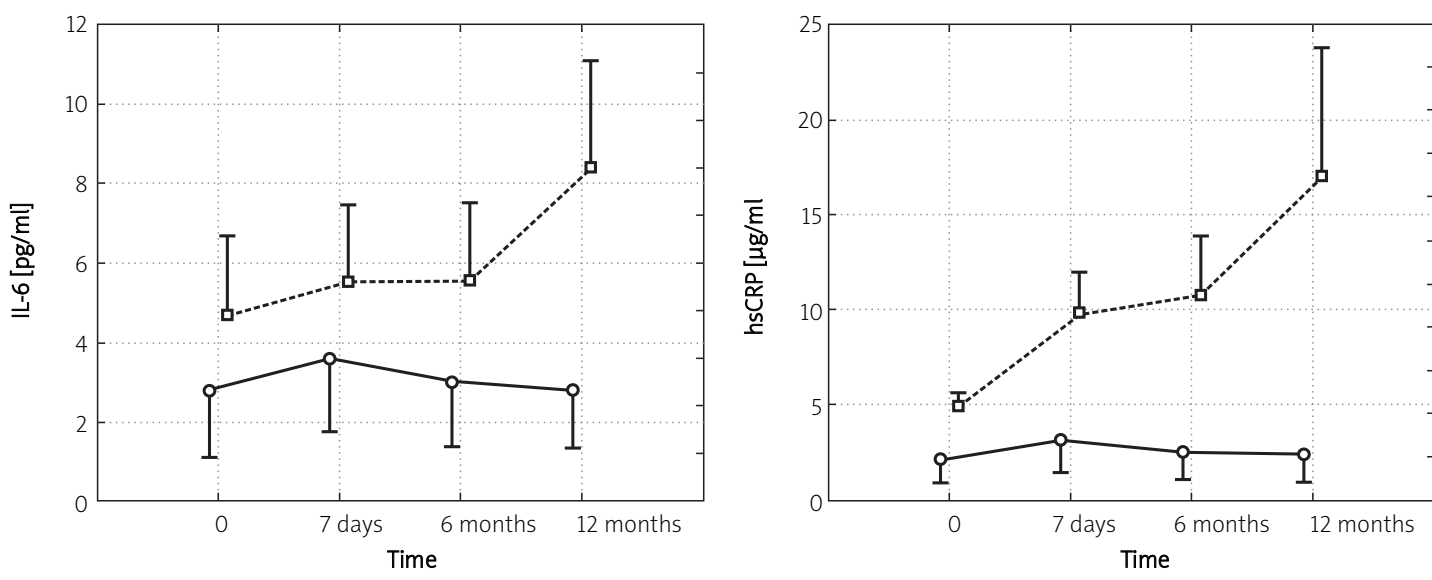

호 $x \pm$ SD Group A 호- $x \pm$ SD Group B

Figure 3. Mean value measurements $(x)$ and standard deviations (SD) of proinflammatory markers in the study groups

Table III. Area under the ROC curve (AUC) and cut-off points for hemodynamic and biochemical parameters before pacemaker implantation

\begin{tabular}{|c|c|c|c|c|c|c|}
\hline Parameters & AUC & $\pm 95 \%(\mathrm{Cl})$ & Value of $p$ & Cut-off & Sensitivity & Specificity \\
\hline LVEDD [mm] & 0.853 & $0.757-0.922$ & $<0.0001$ & $>58$ & 100 & 71.8 \\
\hline EF [\%] & 0.865 & $0.772-0.931$ & $<0.0001$ & $\leq 35$ & 90 & 83.1 \\
\hline D-dimers [ng/ml] & 1.000 & $0.955-1.000$ & $<0.0001$ & $>498$ & 100 & 100 \\
\hline Fibrinogen $[\mathrm{mg} / \mathrm{ml}]$ & 0.987 & $0.933-1.000$ & $<0.0001$ & $>4.7$ & 100 & 88.7 \\
\hline $\mathrm{TF}[\mathrm{ng} / \mathrm{ml}]$ & 0.976 & $0.915-0.997$ & $<0.0001$ & $>300$ & 100 & 94.4 \\
\hline VII [\%] & 0.901 & $0.815-0.957$ & $<0.0001$ & $>99$ & 100 & 67.6 \\
\hline PAl-1 [ng/ml] & 0.942 & $0.866-0.982$ & $<0.0001$ & $>17$ & 100 & 85.9 \\
\hline $\mathrm{IL}-6[\mathrm{pg} / \mathrm{ml}]$ & 0.778 & $0.672-0.863$ & 0.0001 & $>2.45$ & 90 & 60.6 \\
\hline $\mathrm{hsCRP}[\mu \mathrm{g} / \mathrm{ml}]$ & 0.967 & 0.901-0.994 & $<0.0001$ & $>3$ & 100 & 81.7 \\
\hline
\end{tabular}

Table IV. Logistic regression analysis of hemodynamic and biochemical parameters before pacemaker implantation

\begin{tabular}{|c|c|c|c|}
\hline Parameters & Value of $p$ & Odds ratio (OR) & $\pm 95 \%(\mathrm{Cl})$ \\
\hline LVEDD [mm] & 0.003 & 1.183 & $1.059-1.321$ \\
\hline $\mathrm{EF}[\%]$ & 0.003 & 0.895 & $0.833-0.962$ \\
\hline D-dimers [ng/ml] & 0.001 & 590.5 & $40.203-24760$ \\
\hline Fibrinogen $[\mathrm{mg} / \mathrm{ml}]$ & 0.022 & 227.5 & $2.225-22848$ \\
\hline $\mathrm{TF}[\mathrm{ng} / \mathrm{ml}]$ & 0.001 & 189.8 & $15.42-7280$ \\
\hline VII [\%] & 0.002 & 1.145 & $1.05-1.248$ \\
\hline PAI-1 [ng/ml] & 0.001 & 1.674 & $1.231-2.278$ \\
\hline $\mathrm{IL}-6[\mathrm{pg} / \mathrm{ml}]$ & 0.006 & 1.703 & $1.168-2.484$ \\
\hline $\mathrm{hsCRP}[\mu \mathrm{g} / \mathrm{ml}]$ & 0.005 & 26.64 & $2.77-257$ \\
\hline
\end{tabular}

at risk of subsequent venous thrombosis. Patients in group B had worse systolic (lower EF) and diastolic (lower Vp and higher left ventricular diameter) left ventricular function and were characterized by a more pronounced inflammatory and prothrombotic status than those in group $\mathrm{A}$. The highest risk for venous thrombosis incidence was correlated with D-dimers, fibrinogen and tissue factor. The potential relation between these markers and heart failure also seems important. These biochemical markers and hemodynamic factors can be used (together) as screening (selecting patients at high risk) criteria in a future meta-analysis.

Due to the small sample size and relatively short follow-up, multivariate analysis of interactions between various markers of thrombotic risk and pa- 
tients' past medical history could not be performed. It would also be interesting to analyze genetic factors predisposing to VT and such a study is underway.

In conclusion, patients with venous thrombosis after pacemaker implantation had increased levels of laboratory prothrombotic and proinflammatory markers prior to implantation, which continued to rise at follow-up. Levels of D-dimers, fibrinogen and tissue factor were the most powerful biochemical predictors of venous thrombosis.

\section{References}

1. Oginosawa Y, Abe H, Nakashima Y. The incidence and risk factors for venous obstruction after implantation of transvenous pacing leads. Pacing Clin Electrophysiol 2002; 25: 1605-11.

2. Neuwirth J, Bohutová J, Kolár J, Kautzner J, Novák M. DSA diagnosis of pulmonary embolization from intracardial thrombus in a patient with permanent pacing catheter. Pacing Clin Electrophysiol 1990; 13: 7-10.

3. Martinez-Sellés M, Bueno H, Almendral J, Diaz-Castro O. Pulmonary embolism after pacemaker implantation. Tex Heart Inst J 2001; 28: 318-9.

4. Ravyts M, Hermans K, Stockman D. Superior vena cava syndrome and infection of pacing leads in one patient. Acta Cardiol 2002; 57: 309-11.

5. Mazzetti H, Dussaut A, Tentori C, Dussaut E, Lazzari JO. Superior vena cava occlusion and/or syndrome related to pacemaker leads. Am Heart J 1993; 125: 831-7.

6. Żebrowski MR, Krucka A, Bednarkiewicz Z, Religa W. Complications of cardiac pacing. Part II. Thromboembolic complications. Forum Kardiologów 2004; 9: 31-4.

7. Rozmus G, Daubert JP, Huang DT, Rosero S, Hall B, Francis C. Venous thrombosis and stenosis after implantation of pacemakers and defibrillators. J Intervent Cardiac Electrophysiol 2005; 13: 9-19.

8. Bracke FA, Meijer A, van Gelder LM. Pacemaker lead complications: when is extraction appropriate and what can we learn from published data? Heart 2001; 85: 254-9.

9. Goudevenos JA, Reid PG, Adams PC, Holden MP, Williams DO. Pacemaker-induced superior vena cava syndrome: report of four cases and review of the literature. Pacing Clin Electrophysiol 1989; 12: 1890-5.

10. Lelakowski J. Lead-dependent superior vena cava syndrome and occlusion of innominate vein and left subclavian vein as a clinical problem. Folia Cardiol Exer 2009; 4: 105-9.

11. Banach M, Markuszewski L, Zasłonka J, Grzegorczyk J, Okoński P, Jegier B. The role of inflammation in the pathogenesis of atherosclerosis [Polish]. Przegl Epidemiol 2004; 58: 663-70.

12. Bielecka-Dąbrowa A, Wierzbicka M, Goch JH. Proinflammatory cytokines in cardiovascular diseases as potential therapeutic target [Polish]. Wiad Lek 2007; 60: 433-8.

13. Iskra T, Turaj W, Słowik A, Zwolińska G, Strojny J, Szczudlik A. Hemostatic markers of endothelial injury in ischaemic stroke caused by large or small vessel disease [Polish]. Pol Merkur Lekarski 2006; 125: 429-33.

14. Kotschy M, Kotschy D, Witkiewicz W. The role of tissue fac tor and tissue factor pathway inhibitor in blood coagula tion and in thrombotic complications [Polish]. Kardiol Pol 2010; 68: 1158-62.

15. Walczak B, Demkow U, Fijałkowska U. Methods of estimating concentration of the D-dimers used in venous throm boembolism diagnosis. Pneumonol Alergol Pol 2009; 77: 264-70.
16. Ząbczyk M, Butenas S, Palka I, Nessler J, Undas A. Active tissue factor and activated factor $\mathrm{XI}$ in circulating blood of patients with systolic heart failure due to ischemic cardiomyopathy. Pol Arch Med Wew 2010; 120: 334-40.

17. Lelakowski J, Majewski J, Ząbek A, Małecka B, Kuniewicz M, Kafara M. Venous thrombosis as a clinical problem after pacemaker implantation - case report [Polish]. Pol Merkur Lekarski 2010; 169: 41-3.

18. Swinkels BM, Ophuis AJ, Zegers ES, Hertzberger DP, Meursing BT. Recurrent pacemaker lead induced axillary subclavian vein thrombosis. Pacing Clin Electrophysiol 2001; 24: 910-11.

19. Ito T, Tanouchi J, Kawabata M, et al. Superior vena cava syndrome due to a permanent transvenous pacing lead. Jpn Circ J 1996; 60: 707-9.

20. Barakat K, Robinson NM, Spurrell RA. Transvenous pacing lead-induced thrombosis: a series of cases with a review of the literature. Cardiology 2000; 93: 142-8.

21. Lelakowski J, Rydlewska A, Domagała TB, et al. Venous thrombosis as a complication of pacemaker implantation own observations [Polish]. Pol Merkur Lekarski 2011; 176: 103-10.

22. Korkeila P, Nyman K, Ylitalo A, et al. Venous obstruction after pacemaker implantation. Pacing Clin Electrophysiol 2007; 30: 199-206. 